\title{
Designing an loT-based System to Detect the Out-of-pitch Balls in a Football Match
}

\author{
Muhammad Aniq Abqari Rahizad ${ }^{1}$, Tajul Rosli Razak ${ }^{2 *}$, Shukor Sanim Mohd Fauzi \\ Ray Adderley JM Gining ${ }^{4}$, Mohammad Hafiz Ismail ${ }^{5}$ \\ 1,2,3,4,5 Faculty of Computer and Mathematical Science, \\ Universiti Teknologi MARA, Perlis Branch, Arau Campus, 02600 Arau, Perlis, Malaysia \\ Corresponding author: *tajulrosli@uitm.edu.my \\ Received Date: 2 October 2020 \\ Accepted Date: 16 October 2020
}

\begin{abstract}
The incorrect decision-making by the referee made during a football match causes the game unsatisfactory or a biased game. Thus, this problem has become a furious debate among football fans. The fans, as well as players, are dissatisfied when the referee decides specific decisions such as 'a goal or no goal', 'penalty or no penalty' and 'direct red card'. Henceforth, there must be a plan to tackle the problem by using technology, especially in this era. In this paper, as an initial approach, we propose a simple manner of developing a design for the ball out detection using the aid of the IoT (Internet of Things). Specifically, the IoT approach was used for detecting the out-of-pitch balls in a football match. Note that this proposed design was built based on data obtained from a survey questionnaire conducted with the football experts and fans regarding the detection of out-of-pitch balls in a football match. The finding suggested that the proposed design promising to improve the decision-making made in the football match. It is hoped that the study can contribute to the improvement of overall decision making by the referee when coming to the detection of out-of-pitch balls in a football match.
\end{abstract}

Keywords: IoT-Based, Designing IoT, Ball out detection

\section{INTRODUCTION}

Football games are a popular sport in many countries. The referee is the one that will control the flow of the game on the pitch. Consequently, referee decision-making plays an essential function to improve the quality of the game. Also, the outcome of a match may be affected by decisions made by a referee or umpire. In some instances, a single decision will shift the game flow.

In some cases, for example, to determine the ultimate winner, referees sometimes have to make difficult decisions during the match (Groot, 2005). Therefore, these referees demand to know several rules of information games to make sure their result is to keep fair play and prevent the players' conflict. Research had shown that decision-making made by the referee in the field is challenging because of influencing by crowd noise, particularly on the ball out decision. It is also challenging to compare the decisions made in each football game, even from the same referee. In additionally, Balmer et al. (Balmer et al., 2007) indicated that the decision-making process under crowd pressure might be handled through the development of qualitative research. Thus, these critical issues may not be neglected in a quantitative experiment study. There are many ways to help referees to get an accurate decision.

Recently, advanced technology has been introduced to assist referee decision making, such as Video Assist Referee (VAR). According to (Nevill et al., 2002), VAR is an approach used as a support mechanism for the match referee. A team of qualified referees were assessing the game and allowed to 
communicate with the match referee via earpiece. For example, they may provide a suggestion if specific "clear errors" and "missed key decisions" are reviewed by VAR. Although this VAR gives a good result, it still has some issues on the ball out of play decision. The biggest concern is that the system may consume more time during a match as the review process need to be accurately analyzed by VAR. Besides, an incorrect offside call (due to plain and simple human error) by the Assistant Referee (AR), may result in the winning goal or indeed prevented the winning goal. This might cause debate among fans in bars and pubs or on the way home after the game. Also, this is now somewhat removed the equation with the advent of VAR (Carlos et al., 2019). Several approaches may be possible to help the referee decision-making, e.g. using a line detection system.

The Internet of Things (IoT) may help people live and work smarter as well as gain complete control over their lives (Rouse, n.d.). For example, following the issues that happen in VAR decision, the line detection system uses the IoT which evolved machine-to-machine communication without human interaction may be introduced. This is due to the devices connecting via a network.

In this study, an initial design of IoT-based systems on detection out-of-pitch balls in a football match is proposed, to improve the quality of referee results, and consequently improve overall football game outcomes. Also, the findings hope to provide insight into further studies and possible trials with technologies to assist the referee in providing fair competition.

\section{MOTIVATION}

An approach is needed to improve referee decision-making. At present, the chief referee is referred to as the centre referee, which assists by two assistant referees (as linesmen), and the fourth referee who monitors substitutions, among other things. Recently, advanced technology, namely VAR, has been used to help referee decide their decision on the 4-four key categories, namely (i) the goal or no goal, (ii) penalty or no penalty, (iii) direct red card, and (iv) mistaken identity (White, 2020).

The referee tends to make a mistake when they have an instantaneous time to make decisions and sometimes may give an incorrect judgment. Some researchers claimed that various factors contribute to such mistakes, e.g. AR may make mistakes on approximately 20-26\% of offside calls (Mallo et al., 2012). Additionally, to maintain a suitable position, AR makes more errors when they are running than walking or stationary. Besides, research from Professional Game Match Officials (PGMO) shown that the referees make an average of 245 decisions per 90-min match, one every 22 seconds in March 2017. On average, a number that has not changed significantly, which they get five of those decisions wrong (Mallo et al., 2012).

Due to these issues, it is worth introducing a simple design in developing an IoT-based system. This study aims to improve and help the quality of referee decision-making during the match, mainly to track the out-of-pitch balls in a football match.

\section{PROPOSED IOT-BASED METHOD}

In this section, we discuss the IoT-based system for out-of-pitch balls in a football match. Specifically, there are five key phases involved in this study include (i) planning; (ii) information gathering; (iii) preliminary study; (iv) design; and (v) development. These phases are described in detail in the following subsection. 


\section{Planning phase}

The planning phase is essential in this study. This phase required a feasibility study to gain a better understanding and knowledge of the study. The feasibility study comprises of the problem statement, the research question and interview, the objective, the scope and the significance of the study. Furthermore, these activities can be done by reviewing the related journals and discussion with the lecturer and supervisor. The planning phase also will discover the resources which can be used to ensure the process of the implementation is done correctly.

\section{Information gathering phase}

The next phase is the information-gathering phase which concerning the collecting of information based on referee decision making, technology being used and the implementation of IoT project. This also can be accomplished by reviewing existing journal, article, newspaper, book or any relevant sources are collected to review and delivered in the literature. Additionally, we have surveyed 52 responses from all types of age, mainly football fans. Note that this questionnaire is a preliminary investigation to gain feedback from football fans.

\section{Preliminary study phase}

In this phase, the interview with the referees in Universiti Teknologi MARA (UiTM), Perlis Branch was conducted. Five judges of different ages and experiences were selected to answer the four essential questions during the interview session.

For the first question, all referees need to provide all answers regarding a fault occurs. This question aims to assess how influential the referee to have a look at a mistake made by a player. Hence, this study confirms that the referees need an assistant to help that to check the error made by players. The second question is to establish how accurate the decision made by the referee. These results found that most referees make mistakes when giving decisions for errors made by players. Additionally, this also proves that a wrong decision by the referee may affect the flow of games.

For the third question, it confirmed that assistant referees do not adequately assist the decision referee due to limited view. Also, most interviewers gave negative feedback on the issue of raising the flag late. For instance, in some situations, the ball is entirely out of the field. However, the assistant referee did not notice it. Interestingly, the question regarding the detection of the out-of-pitch balls in a football match, most referees agreed to have it as it may help them gets a better result.

The fourth question is focusing on whether the referee requires supplementary technology as their assistant to supply the correct decision. Finally, to conclude the study from this interview, the analysis suggests that referees need technology as a platform for them to give accurate decisions. Therefore, IoTbased system is demanded to support the referee decision making.

\section{Design Phase}

Figure 4 shows the research design, which includes tools used for this study. This phase intends to shape and get the best solution to the problem specified in the required forms. It was constructed to reflect the observation that had been done before. The prototype is designed to record the time taken for the out-ofpitch balls in a football match. Also, analysis on each part of the ball out from the football pitch is produced. 


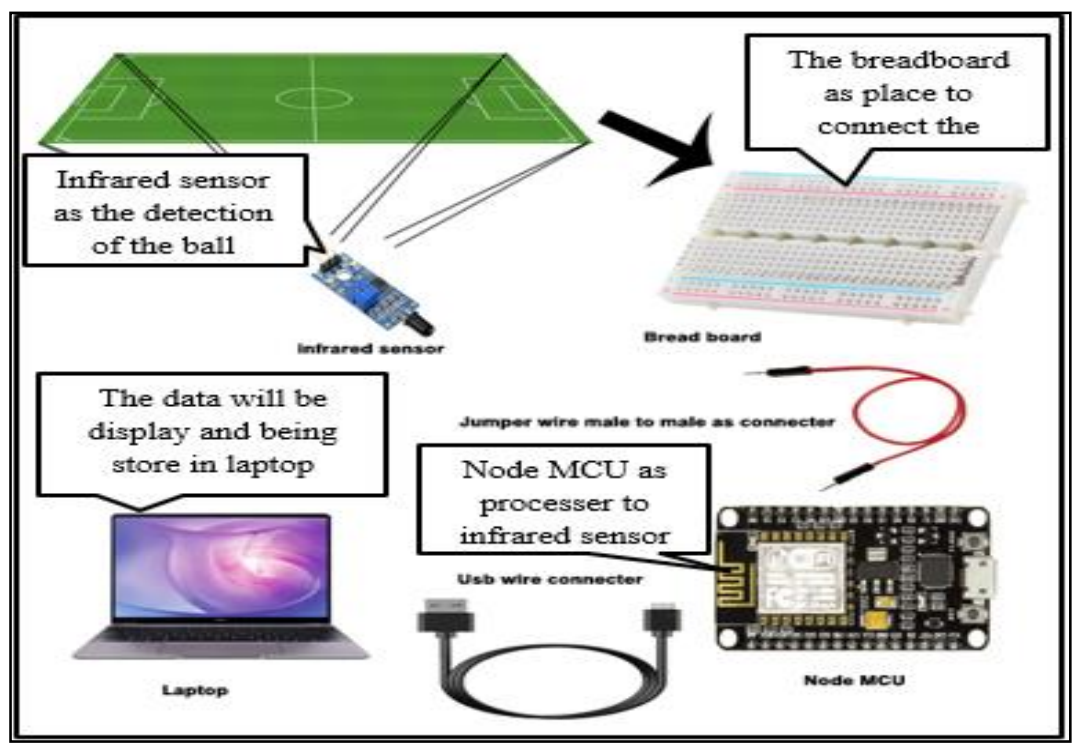

Figure 4. The tools involved in the proposed loT-based design

Specifically, the design incorporates Node MCU, breadboard, jumper wire male to male, Universal Serial Bus (USB) wire and laptop to display the output, as shown in Figure 4. The breadboard will be connected with infrared sensors at the corner according to their section. The infrared sensors will then detect the ball when it passes through the sensor. Consequently, the led will light up as the notification. The notification result will then appear on the screen laptop and stored in the MySQL database. Also, the breadboard was joined with Arduino Uno using the jumper wire male to male.

\section{Development Phase}

Next, the development phase includes coding and compose the prototype. This prototype may look simple, but it is different from the others as it was explicitly produced based on the results obtained during the preliminary study phase, as shown in Figure 5.

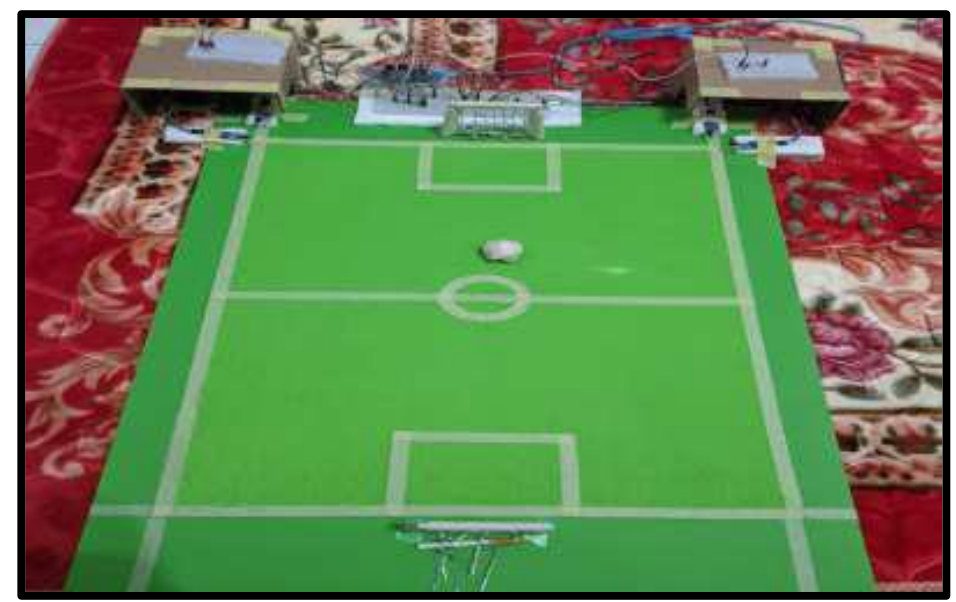

Figure 5. The prototype of a football pitch that combining the sensors. 
Then all the knowledge (from the previous phase) will be transformed into the computer program using the Arduino IDE. For instance, the sensor will produce red light to warn the referee if the ball has been outside the line, as can be seen in Figure 6.

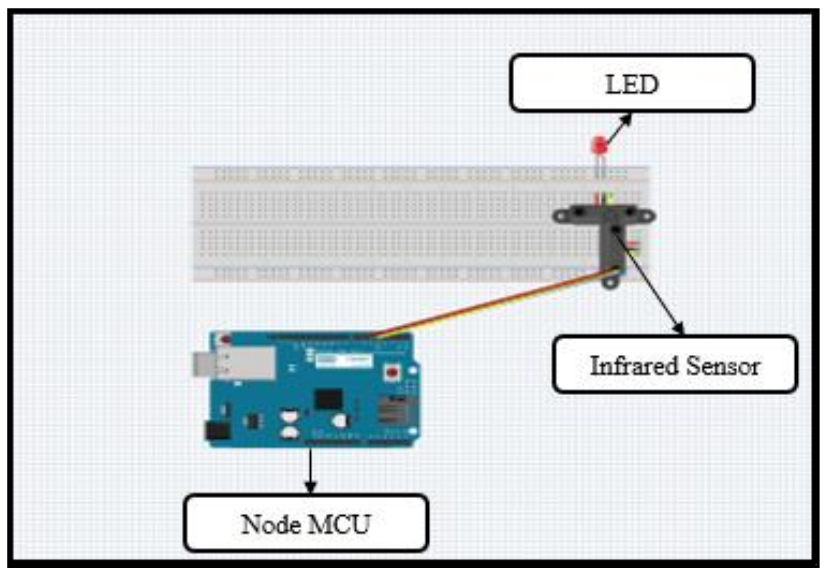

Figure 6. The example of implementation processes.

\section{EVALUATION AND RESULTS}

This section aims to assess the proposed IoT-based design for out-of-pitch balls in a football match. That is, we use a well-known testing approach, namely user functionality testing and user acceptance test. Also, an initial result is observed and discussed in the following subsection.

\section{User functionality testing (user)}

Functional testing is a process of ensuring quality. It is also well acknowledged as black-box testing, based on the software component module under test in its test cases (Ghuman, 2014). In this study, the functionality testing was conducted to verify the process of detecting ball out of play, alert messages and the transfer data to the database. This testing has been performed to people that have background and experience in information technology and sport science. Specifically, these respondents are composed of students and employees ( 21 respondents), where they have to answer ten questions completely, as shown in Table 1.

Table 1: The result of the functionality test

\begin{tabular}{|l|l|l|l|l|l|}
$\mathbf{T}$ Task & Description & $\begin{array}{l}\text { Yes } \\
(\boldsymbol{\%})\end{array}$ & $\begin{array}{l}\text { No } \\
(\mathbf{\%})\end{array}$ & $\begin{array}{c}\text { Maybe } \\
(\mathbf{\%})\end{array}$ & Result \\
\hline $\mathbf{1}$ & $\begin{array}{l}\text { An infrared sensor is detecting which section that ball was } \\
\text { out. }\end{array}$ & 100 & - & - & Pass \\
\hline $\mathbf{2}$ & $\begin{array}{l}\text { Each sensor of each section is showing the ball out when the } \\
\text { ball out of line. }\end{array}$ & 85.7 & - & 14.3 & Pass \\
\hline $\mathbf{3}$ & $\begin{array}{l}\text { The infrared sensor displays the data of each section on the } \\
\text { database for every time the ball past the outline. }\end{array}$ & 95.2 & - & 4.8 & Pass \\
\hline
\end{tabular}




\begin{tabular}{|c|c|c|c|c|c|}
\hline 4 & LEDs are lighting up when the ball already out of the line. & 95.2 & - & 4.8 & Pass \\
\hline 5 & $\begin{array}{l}\text { The web page displays the details after it is updated on the } \\
\text { database. }\end{array}$ & 95.2 & - & 4.8 & Pass \\
\hline 6 & The value 0 shows on the web page when the LED is light up. & 90.5 & - & 9.5 & Pass \\
\hline 7 & $\begin{array}{l}\text { The value } 1 \text { shows on the web page when the LED does not } \\
\text { light up. }\end{array}$ & 76.2 & - & 23.8 & Pass \\
\hline
\end{tabular}

In general, the results show that the proposed IoT-based design is functional and usable, in terms of functional testing, as can be seen in Table 1. Based on the current evidence, it can be concluded that the proposed IoT-based design promising and had met the goal of this study. That is, it may help the referee to make a better decision when it comes to detection of out-of-pitch balls in a football match. Consequently, it offers an alternative to improve the problem of referee decision making during the football match.

\section{User Acceptance test (UAT)}

User Acceptance Testing (UAT), also known as beta or end-user testing, is described as experts as reviewing the project to decide if it is appropriate or not. This is the final testing on completion of the functional, model and regression tests (Camilleri et al., 2020). Acceptance testing is introduced user's confidence that the development product is fit for intention (Pandit \& Tahiliani, 2015).

The proposed design was tested by experts to validate product implementation. It is essential especially to see how a project reacts to a real situation football game. They (experts) will consider the functionality of specific goals which could create unnecessary frustration and irritations among the users-often ending up in the end-users altogether abandoning expensive products.

This testing includes ten experts aged from 20 to 40 years old. Before start answering the questions, these respondents (ten experts) have been provided with a short video regarding the proposed system. Specifically, the video explains how the project work. Other than that, the respondents were provided with a set of questionnaires containing nine questions. The analysis was evaluated based on the questionnaire from the questions provided to them, as can be seen in Tables $2-4$.

\section{Discussion on UAT}

In the user acceptance test, it consists of nine questions that focus more on the content of the proposed design. Notably, the analysis of perceived was divided into three sub-components, as shown in Tables $2-$ 4. In summary, based on the current evidence, the user functionality test showed the proposed designed was satisfied by experts. Despite the fact that we only tested with ten experts, in general, based on this available evidence, user functionality tests have proven that all experts approve this proposed IoT-based design for out-of-pitch balls in a football match. 
Table 2: The perceived ease of use

\begin{tabular}{|c|c|c|}
\hline No. & Questions & $\begin{array}{l}\text { Mean Rating } \\
\text { from } 1 \text { to } 5 .\end{array}$ \\
\hline 1 & $\begin{array}{l}\text { The system demonstration is easy to use for the referee to detect ball out } \\
\text { during the match }\end{array}$ & 4.5 \\
\hline 2 & $\begin{array}{l}\text { The task to be performed can be predicted as the system is easy to } \\
\text { understand }\end{array}$ & 4.5 \\
\hline 3 & The system is comfortable to use by the referee during the match & 4.5 \\
\hline 4 & The referee will be able to use this system since it is not complex & 4.4 \\
\hline \multicolumn{2}{|r|}{ Overall mean rating } & 4.475 \\
\hline
\end{tabular}

Table 3: The perceived intention of use

\begin{tabular}{|l|l|c|} 
No. & \multicolumn{1}{|c|}{ Questions } & $\begin{array}{c}\text { Mean Rating } \\
\text { from 1 to 5. }\end{array}$ \\
\hline $\mathbf{1}$ & $\begin{array}{l}\text { If I am a referee during a match, I am willing to use this system to assist } \\
\text { on detection ball out decision. }\end{array}$ & 4.4 \\
\hline $\mathbf{2}$ & $\begin{array}{l}\text { This system is useful for tracking the ball out of play accurately during a } \\
\text { football match. }\end{array}$ & 4.2 \\
\hline $\mathbf{3}$ & $\begin{array}{l}\text { If I am a referee, I will consider using the system during a match because } \\
\text { of the functions of the system. }\end{array}$ & 4.2 \\
\hline & \multicolumn{1}{|c}{ Overall mean rating } & 4.26 \\
\hline
\end{tabular}

Table 4: The perceived of usefulness

\begin{tabular}{|l|l|c|} 
No. & \multicolumn{1}{|c|}{ Questions } & $\begin{array}{c}\text { Mean Rating } \\
\text { from 1 to 5. }\end{array}$ \\
\hline $\mathbf{1}$ & $\begin{array}{l}\text { This detection balls out system is an effective solution in solving referee } \\
\text { problem when to detect ball out of line play because referee can } \\
\text { understand how to use the system without much difficulty. }\end{array}$ & 4.3 \\
\hline $\mathbf{2}$ & $\begin{array}{l}\text { By using this system, the referee's job becomes more reasonable since the } \\
\text { referee can use it without facing any difficulties. }\end{array}$ & 4.3 \\
\hline $\mathbf{3}$ & $\begin{array}{l}\text { I found this system will enhance the referee's effectiveness in detecting } \\
\text { ball out without the need to do it manually. }\end{array}$ & 4.5 \\
\hline & \multicolumn{2}{|c|}{ Overall mean rating } \\
\hline
\end{tabular}

In general, Tables 2 to 4 present the overall rating from participants. Based on the results obtained, it can be concluded that the participants positively can accept the proposed system, i.e. the IoT-based design for out-of-pitch balls in a football match using infrared sensors. This was shown through the total mean that 
each component obtained after the test, where the overall mean rating was more than 4.0, as in Tables 2 to 4.

\section{CONCLUSION}

In summary, we have proposed an IoT-based design system for detecting the out-of-pitch balls in a football match. Specifically, we have proposed an initial design of IoT-based system that was built based on data obtained from a preliminary study.

The proposed system was then evaluated by a set of respondents in a series of testing. Based on the current evidence, the proposed IoT based systems are promising as agreed by respondents. That is, it might be useful for the referee in order to improve the quality of decision-making during the football match. While the proposed design system is promising, it may be debated as it was too plain. Additionally, one might also argue as only ten experts evaluated the proposed design.

Indeed, this is our initial approach to the IoT-based design for a particular problem. Therefore, for future work, we will improve the proposed IoT-based design by combining it with other high-end sensors and also testing it with a higher number of experts. By doing this, it is hoped to improve the performance of the proposed design IoT system. Consequently, it may be implemented in real situations, such as football..

\section{REFERENCES}

Balmer, N. J., Nevill, A. M., Lane, A. M., Ward, P., Williams, A. M., \& Fairclough, S. H. (2007). Influence of crowd noise on soccer refereeing consistency in soccer. Journal of Sport Behavior, $30(2)$.

Camilleri, G., Antonelli, L., Zaraté, P., Gardey, J., Martin, J., Sakka, A., Torres, D., Fernandez, A., Tool sup-, al, Zarate, P., \& Cruz Gardey, J. (2020). Tool support for Generating User Acceptance Tests. https://hal.archives-ouvertes.fr/hal-02866180

Carlos, L. P., Ezequiel, R., \& Anton, K. (2019). How does Video Assistant Referee (VAR) modify the game in elite soccer? International Journal of Performance Analysis in Sport, 19(4), 646-653. https://doi.org/10.1080/24748668.2019.1646521

Ghuman, S. S. (2014). Software Testing Techniques. International Journal of Computer Science and Mobile Computing, 3(10), 988--993.

Groot, L. (2005). Referees among most important players in soccer tournaments. Journal of Sport and Social Issues, 29(4), 437-442. https://doi.org/10.1177/0193723505280797

Mallo, J., Frutos, P. G., Juárez, D., \& Navarro, E. (2012). Effect of positioning on the accuracy of decision making of association football top-class referees and assistant referees during competitive $\begin{array}{llll}\text { matches. Journal of Sports } & \text { Sciences, } & \text { 30(13), }\end{array}$ https://doi.org/10.1080/02640414.2012.711485

Nevill, A. M., Balmer, N. J., \& Mark Williams, A. (2002). The influence of crowd noise and experience upon refereeing decisions in football. Psychology of Sport and Exercise, 3(4), 261-272. https://doi.org/10.1016/S1469-0292(01)00033-4 
Pandit, P., \& Tahiliani, S. (2015). AgileUAT: A Framework for User Acceptance Testing based on User Stories and Acceptance Criteria. International Journal of Computer Applications, 120(10), 16-21. https://doi.org/10.5120/21262-3533

Rouse, M. (n.d.). What is IoT (Internet of Things) and How Does it Work? Retrieved August 12, 2020, from https://internetofthingsagenda.techtarget.com/definition/Internet-of-Things-IoT

White, J. (2020). VAR chaos and controversy in Champions League tie between Manchester City and Tottenham proves tech is not yet ready. South China Morning Post. https://www.scmp.com/sport/football/article/3006690/var-chaos-and-controversy-championsleague-tie-between-manchester 